UCRL-ID-120499

\title{
Qualification of Box HEPA Filters for Nuclear Applications
}

\author{
W. Bergman \\ G. Larsen \\ K. Wilson \\ F. Rainer
}

March 1995

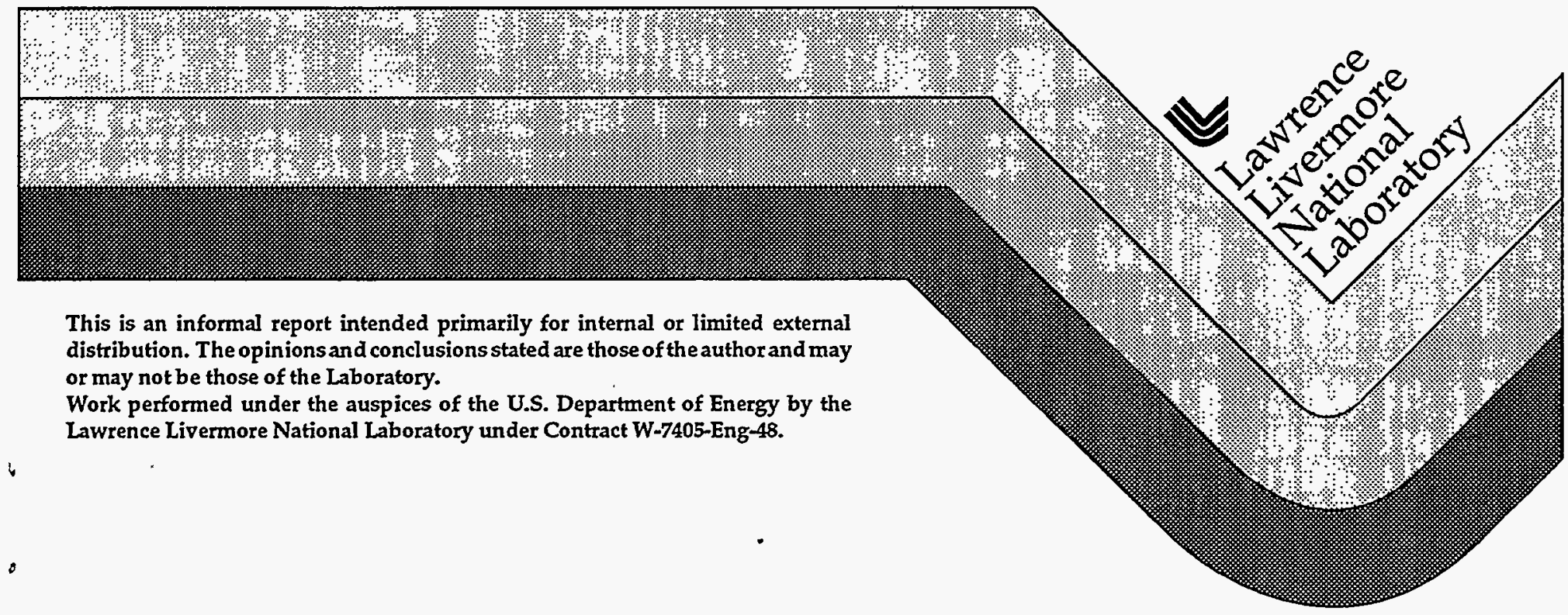




\section{DISCLANMER}

This document was prepared as an accoount of work sponsored by an agency of the United States Government. Neither the United States Government nor the University of California nor any of their employees, makes any warranty, express or implied, or assumes any legal liability or responsibility for the accuracy, completeness, or usefulness of any information, apparatus, product, or process disclosed, or represents that its use would not infringe privately own rights. Reference herein to any specifie commercial products, process, or service by trade name, trademark, manufacturer, or otherwise, does not necessarily constitute or imply its endorsement, recommendation, or favoring by the United States Government or the University of California. The views and opinions of authors expressed herein do not necessarily state or reflect those of the United States Government or the University of California, and shall not be used for advertising or product endorsement purposes.

This report has been reproduced directly from the best available copy.

Available to DOE and DOE contractors from the

Office of Scientific and Technical Information

P.O. Box 62, Oak Ridge, TN 37831

Prices available from (615) 576-8401, FIS 626-8401

Available to the public from the

National Technical Information Service

U.S. Department of Commerce

5285 Port Royal Rd.,

Springfield, VA 22161 


\section{DISCLAIMER}

Portions of this document may be illegible in electronic image products. Images are produced from the best available original document. 


\title{
QUALIFICATION OF BOX HEPA FILTERS FOR NUCLEAR APPLICATIONS
}

Werner Bergman, Greg Larsen, Kent Wilson and Frank Rainer ${ }^{1}$

Lawrence Livermore National Laboratory

P.O. Box 5505, Livermore, CA 94550

\begin{abstract}
$\underline{\text { Abstract }}$
We have successfully completed qualification tests on high efficiency particulate air (HEPA) filters that are encapsulated within a box and manufactured by American Air Filters. The qualification tests are required by the American Society of Mechanical Engineers Standard ASME N509 [1] and the U.S. Military Standard MIL-F51068 [2] for HEPA filters to be used in nuclear applications. The qualification tests specify minimum filter efficiencies following exposure to heated air, overpressure, and rough handling. Prior to this study, no box HEPA filters from any manufacturer had been qualified despite their wide-spread use in Department of Energy (DOE) facilities. Box HEPA filters are not addressed in any of the existing HEPA standards and only briefly discussed in the Nuclear Air Cleaning Handbook [3].
\end{abstract}

\section{Introduction}

All HEPA filters designated as a safety class item in DOE nuclear facilities must be qualified for resistance to heated air, overpressure and rough handling to assure that the filters will perform as intended during most off-normal and accident conditions. The tests are specified in the ASME N509 [1] and MIL-F-51068 [2] standards, which require that every manufacturer have each of their HEPA filter models pass the qualification test every five years. Filters having different designs and materials must have separate qualification tests. It is possible to have a large number of different filter models depending on the filter media pack (deep pleated with corrugated aluminum separators, mini pleated with string or tape

1EG\&G Rocky Flats, Inc. Golden, CO 80402 
separators, and deep pleated with no separators), frame design (open face, boxed) and choice of materials for the frame, sealant and media. HEPA filters made with each combination of parameters require separate qualification tests. If HEPA filters are used as an engineered safety feature (ESF) then ASME N509 also requires the HEPA filter to have a metal frame if the frame serves as a wall of the ventilation duct. This requirement assures that the ventilation system will not be breached during a fire.

A unique HEPA filter design has the filter media pack encapsulated in a box with an inlet and exit port. Figures 1 and 2 show the front and side view of a $1,000 \mathrm{cfm}$ box HEPA from American Air Filter respectively. The filter media pack, which can be seen through the inlet duct in Figure 1, is glued to the inside of a plywood frame in the same fashion as the standard open face HEPA filter. Other frame materials such as stainless steel are also available. The distinguishing feature of box HEPA filter is the frame, which extends slightly beyond the filter pack and has a restricted inlet and exit port. The net effect is the encapsulation of the filter medium within a box, hence the name box HEPA. The advantage of this design is that the HEPA filter is readily installed or removed by clamping and unclamping to and from air ducts. Moreover, this design reduces worker and workplace contamination during filter change out because the contaminated media is contained inside the box. A major disadvantage of the box HEPA filter is the increased quantity of radioactive waste compared to the open face design. However, for applications that have infrequent filter changes, the advantages outweigh the disadvantages.

Although the box HEPA filters have been used in DOE facilities for many years, they have never had the required qualification tests. The Nuclear Air Cleaning Handbook [3] stated in 1976 that "currently available enclosed filter units cannot meet the fire- and hot-air resistance requirements of UL-586 [4], nor do wood-cased enclosed filter units meet the requirements of NFPA 90A [5]." More recently, Arndt [6] discussed the lack of filter qualification tests and other test deficiencies and recommended that the box HEPA "filter should not be used for nuclear applications." The fact that box HEPA filters have been and continue to be widely used in DOE facilities represents a serious problem since the filters did not meet the requirements in applicable DOE [7], ASME [1], and military [2] standards. Although the purchase orders from DOE facilities for the box HEPA filters 
required the qualification tests, the filter manufacturers never conducted the tests.

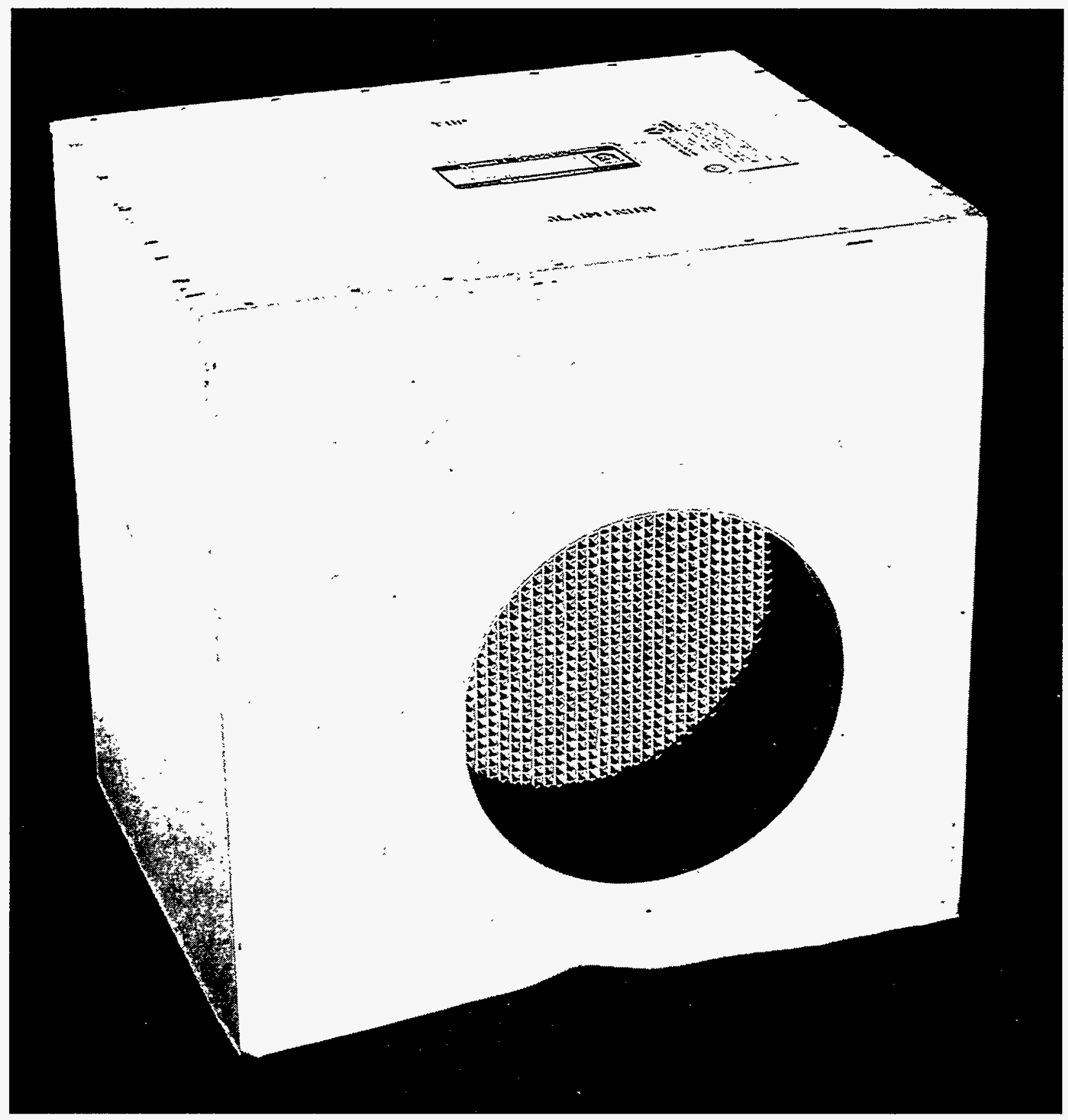

Figure 1. Front view of $1,000 \mathrm{cfm}$ box HEPA filter with filter media pack showing through the inlet duct. The dimensions excluding the ducts are $24^{\prime \prime} \times 24 "$ x 20 ". 


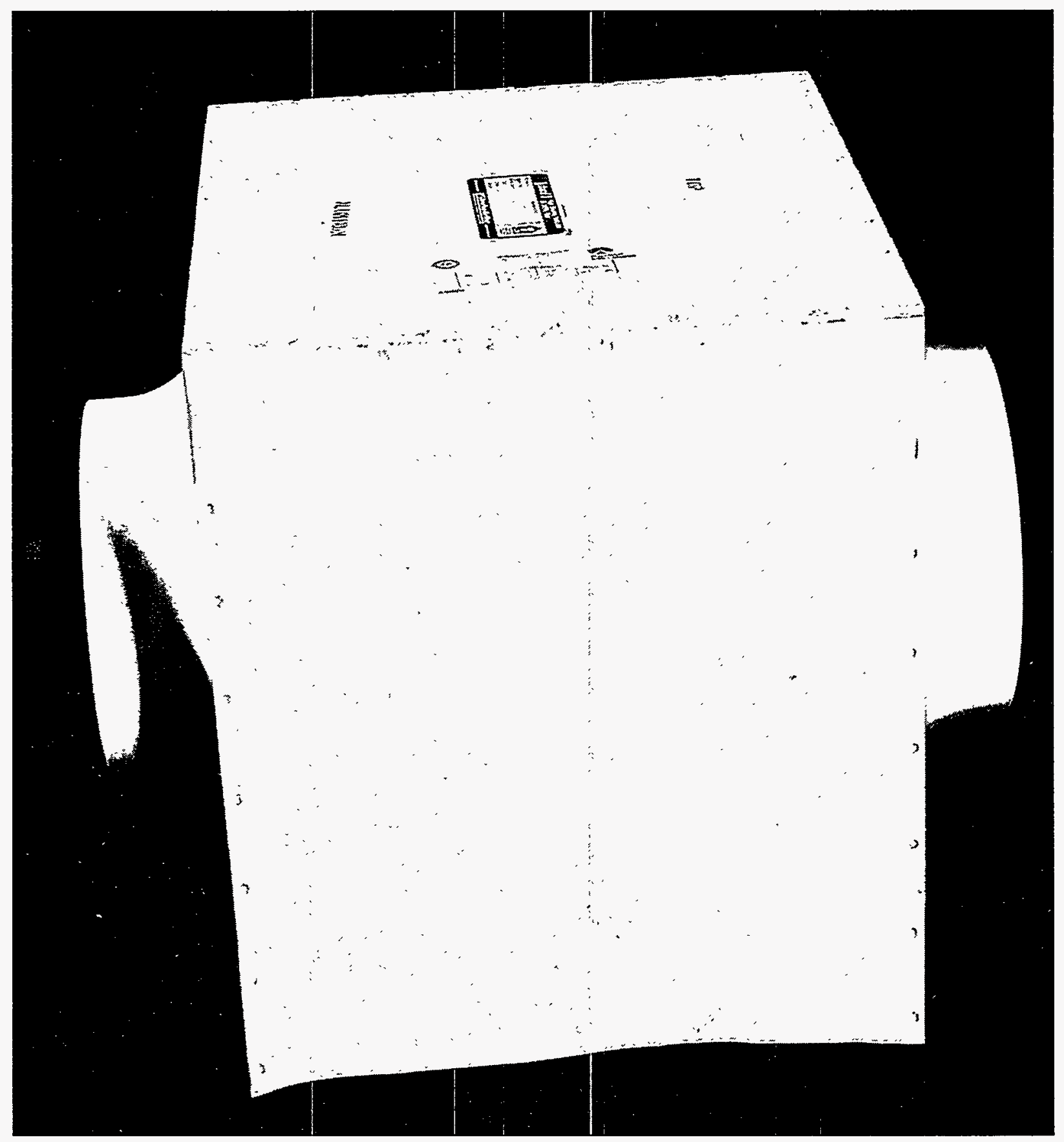

Figure 2. Side view of $1,000 \mathrm{cfm}$ box HEPA filter. The dimensions excluding the inlet and exit ducts are $24 " \mathrm{x}$ $24^{\prime \prime} \times 20^{\prime \prime}$ 
We investigated why the box HEPA filters were never submitted for the qualification tests and discovered that the filters were not fully compatible with existing test equipment for conducting the requisite qualification testing. The three U.S. test facilities at the U.S. Army Edgewood Arsenal, Underwriters Laboratories, and DOE's Rocky Flats Plant could not conduct the qualification tests because the larger box HEPA filters could not fit into the test equipment. Moreover, space limitations prevented modification of the test equipment. In order to conduct the tests, the test equipment would have to be relocated in addition to modifying the filter connections.

Despite the obstacles that prevented testing box HEPA filters in the available test laboratories, we decided to improvise the tests with temporary modifications to both the test equipment and the box HEPA filters in order to conduct the qualification tests. However, no modifications were made that would compromise the validity of the test results.

\section{Filter Qualification Tests}

The three qualification tests that should have been, but were not performed on the box HEPA filters are the heated air test, the pressure resistance test, and the rough handling test. We modified the test equipment at the Rocky Flats Filter Test Facility to accommodate the box HEPA filters in the qualification tests.

\section{Heated Air Test}

The apparatus for the heated air test is shown in the sketch of Figure 3. It consists of a duct containing a blower, a natural gas manifold, adjustable vanes, and a movable exhaust duct that serves as a chuck to hold the filter in the path of the heated air. The Rocky Flats heated air apparatus generates an air flow of 1,000 standard cubic feet of air per minute (SCFM) $\left(1,700 \mathrm{~m}^{3} / \mathrm{hr}\right)$ which is heated to $700^{\circ} \mathrm{F}\left(371^{\circ} \mathrm{C}\right)$. The rig incorporates a number of improvements in design from the original model at the Edgewood Area of Aberdeen Proving Ground, Maryland, and the Underwriters Laboratories apparatus located at Northbrook, Illinois. The test method is described in Underwriters Laboratories Standard UL 586 [4]. 


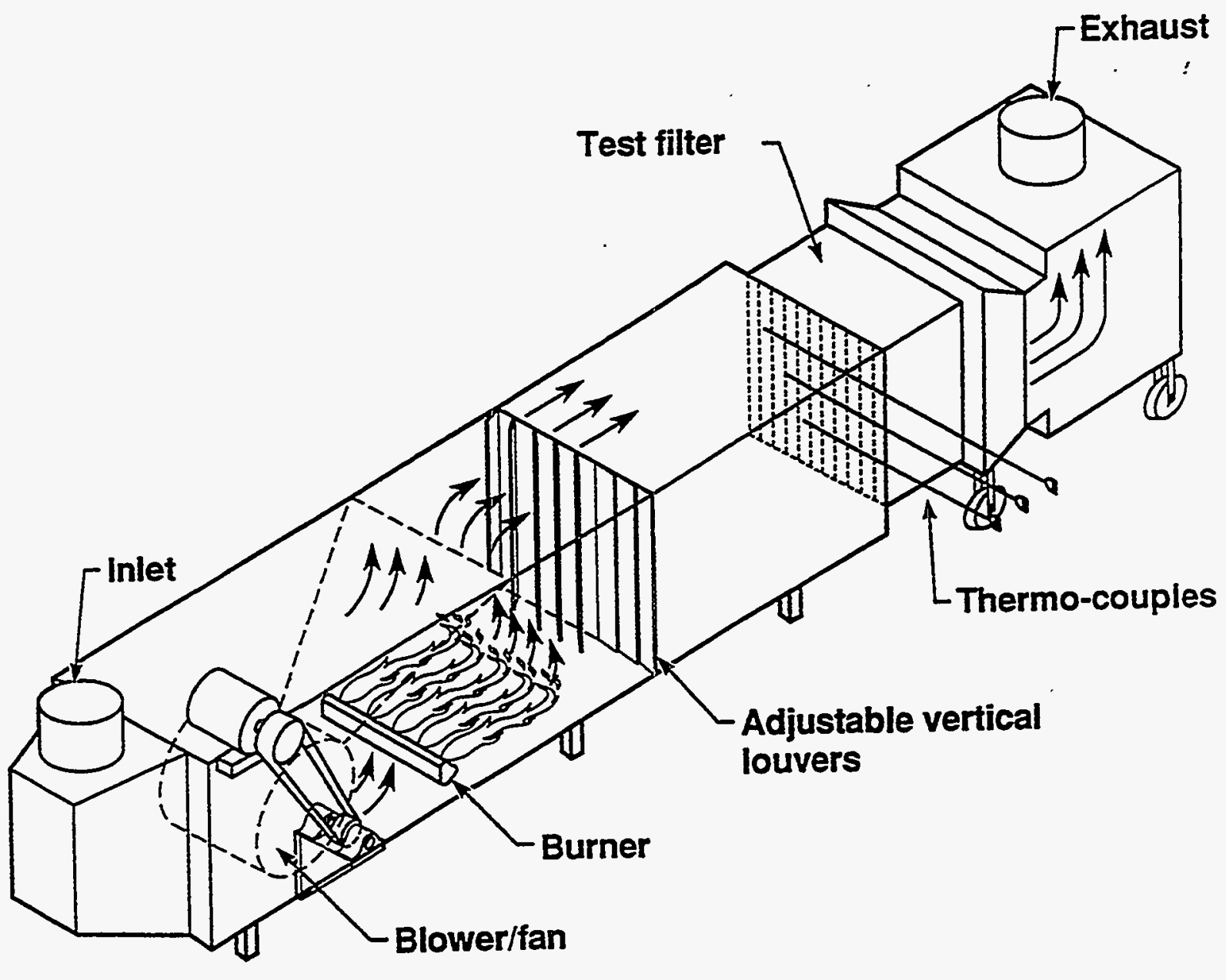

Figure 3 Heated air test apparatus

To evaluate the box HEPA filters in the heated air test, we had to modify both the box HEPA filter and the filter chuck assembly. Figure 4 shows a close up photograph of the filter holding chuck with a standard 24" $\times 24^{\prime \prime} \times 11.5^{\prime \prime}$ HEPA filter clamped between the two sealing plates. The exhaust portion of the duct is mounted on rollers to allow the chuck to be opened and closed for filter installation and removal. To accommodate the wider box HEPA filter $\left(24^{\prime \prime} \times 24 " \mathrm{x}\right.$ 20 "), a new metal flex-duct was installed on the exhaust. However, because there was insufficient room in the building to allow a smooth transition from the square ducts to the 12" round HEPA ducts, the inlet and exit frames of the box HEPA filter were sealed to the chuck faces with a high temperature gasket. The 12" inlet HEPA duct therefore extended into the upstream test duct. We also had to remove the downstream HEPA duct to allow sufficient space for a water spray system in the downstream section of the test duct. Separate thermocouples were installed inside the HEPA filter to 
obtain accurate temperature measurements near the upstream side of the filter medium.

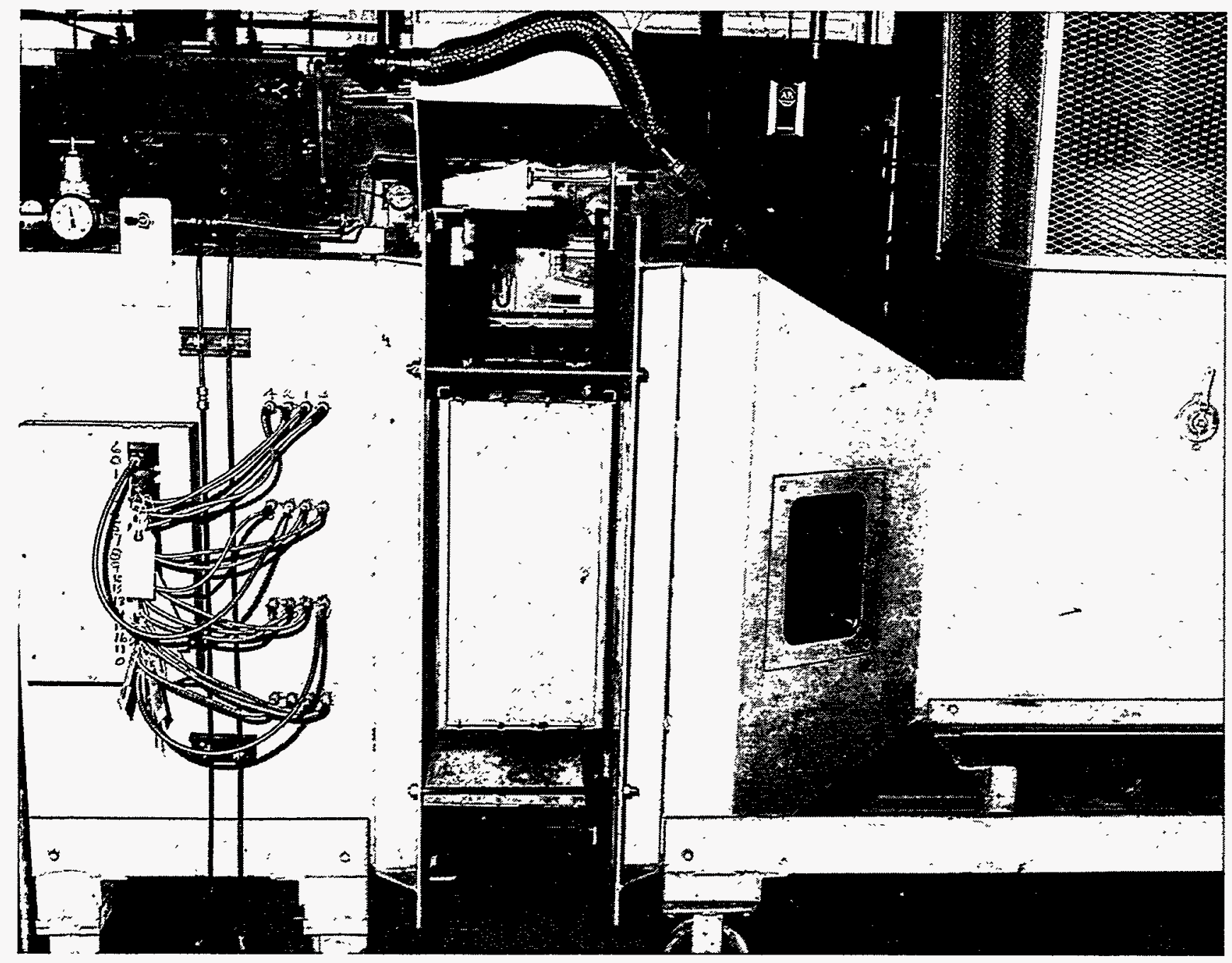

Figure 4 Filter holding chuck with the standard $24 " \times 24 " \times 11.5 "$ HEPA filter

The inability to properly interface the box HEPA filters to the heated air test apparatus did not adversely affect the test results. By placing additional thermocouples inside the HEPA box, we verified that the filter media was subjected to the standard temperature. We also conducted separate measurements of the air flow prior to 
heating the air to assure an adequate air flow. Our measurements showed the flow through the box HEPA filter was $670 \mathrm{cfm}$. The lack of smooth transitions from the test duct to the HEPA filter increased the pressure drop of the HEPA relative to a properly designed test apparatus. Sealing the HEPA filter against the frame also increased the heat stress to the filter frame although this effect was reduced by using a heat blanket to seal the filter to the filter chuck.

The heated air test consists of measuring the HEPA filter efficiency according to Military Standard MIL-STD-282 [8] before and after exposure to the heated air. After installing the box HEPA filter in the test apparatus shown in Figure. 3, the blower was started and the air temperature was brought to $700 \pm 50^{\circ} \mathrm{F}\left(371 \pm 28^{\circ} \mathrm{C}\right)$, at which point the five-minute test began. Following this period of exposure, the gas flame was discontinued, and continued air flow cooled the apparatus to $80-100$ degrees to permit removal of the filter.

\section{Pressure Resistance Test}

The pressure resistance test apparatus is an elongated elliptical chamber through which air and moisture are recirculated to a test filter. A schematic of the Q160 pressure resistance apparatus is shown in Figure 5. The apparatus that we used in this study is housed in the Filter Test Facility at the Rocky Flats Plant and is shown in Figure 6. A standard 24" $\times 24 " \times 11.5$ " filter that is positioned for testing is seen through the access door in Figure 6.

Modifications were made to both the pressure test apparatus and to the box HEPA filters to conduct the tests. The clamping apparatus used to seal the HEPA filter into the housing, as shown in Figure 7 , was replaced with a larger clamp that could accommodate the larger HEPA filter. Pressure taps were also installed on the box HEPA filter to measure the pressure across the media. This was necessary because the inlet and exit ducts of the filter represented a significant fraction of the overall pressure drop across the box HEPA filter. The maximum pressure that the air blower could apply across the box filter was 11.5 inches, while the corresponding measurements across the filter media were only 7.1 and 8.0 inches for two different box filters. To test the filter at the required 10 inches, we cut off both ends of one of the box filters and repeated the test at 10 inch pressure differential. 


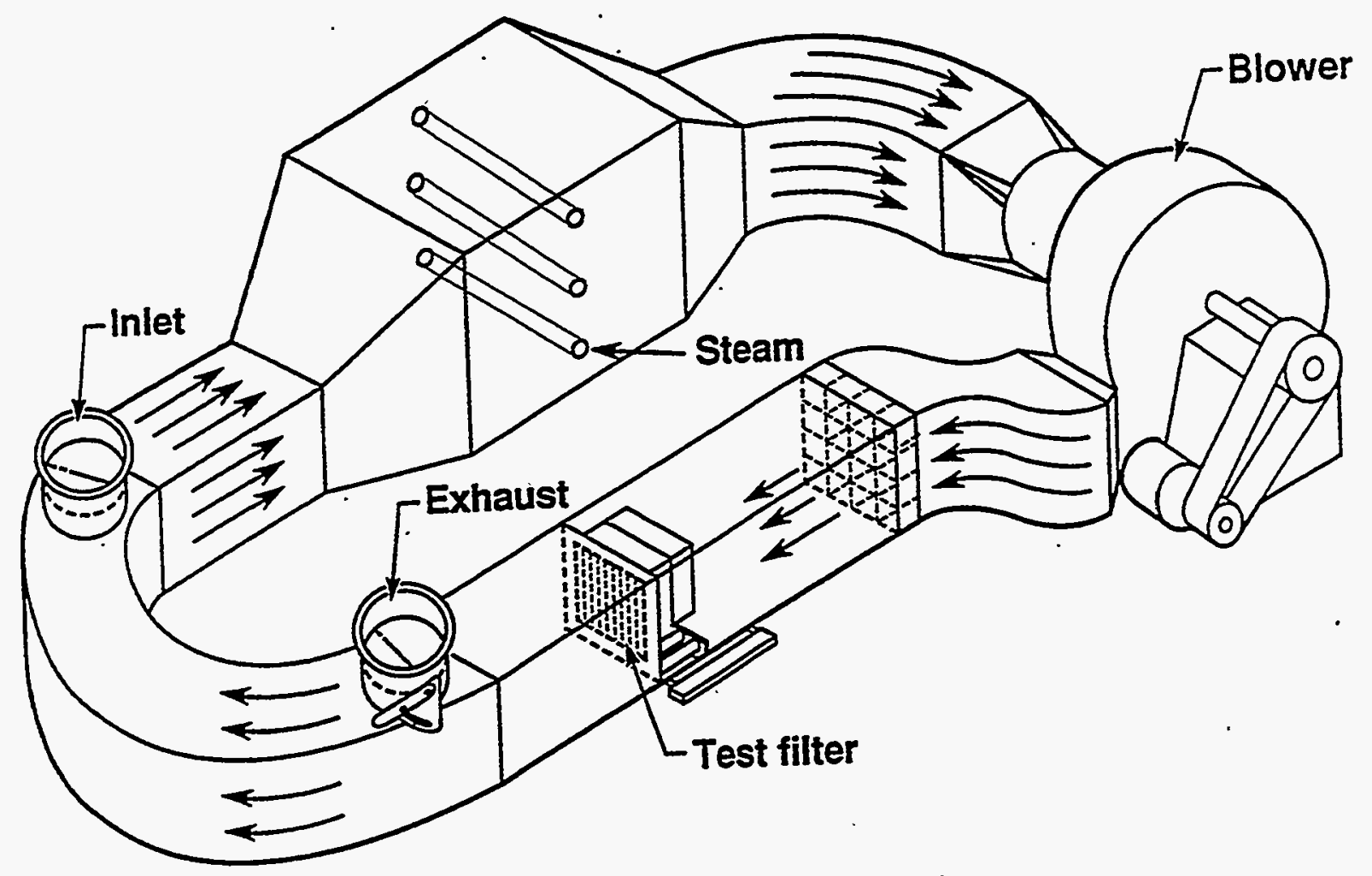

Figure 5 Diagram of the pressure resistance apparatus

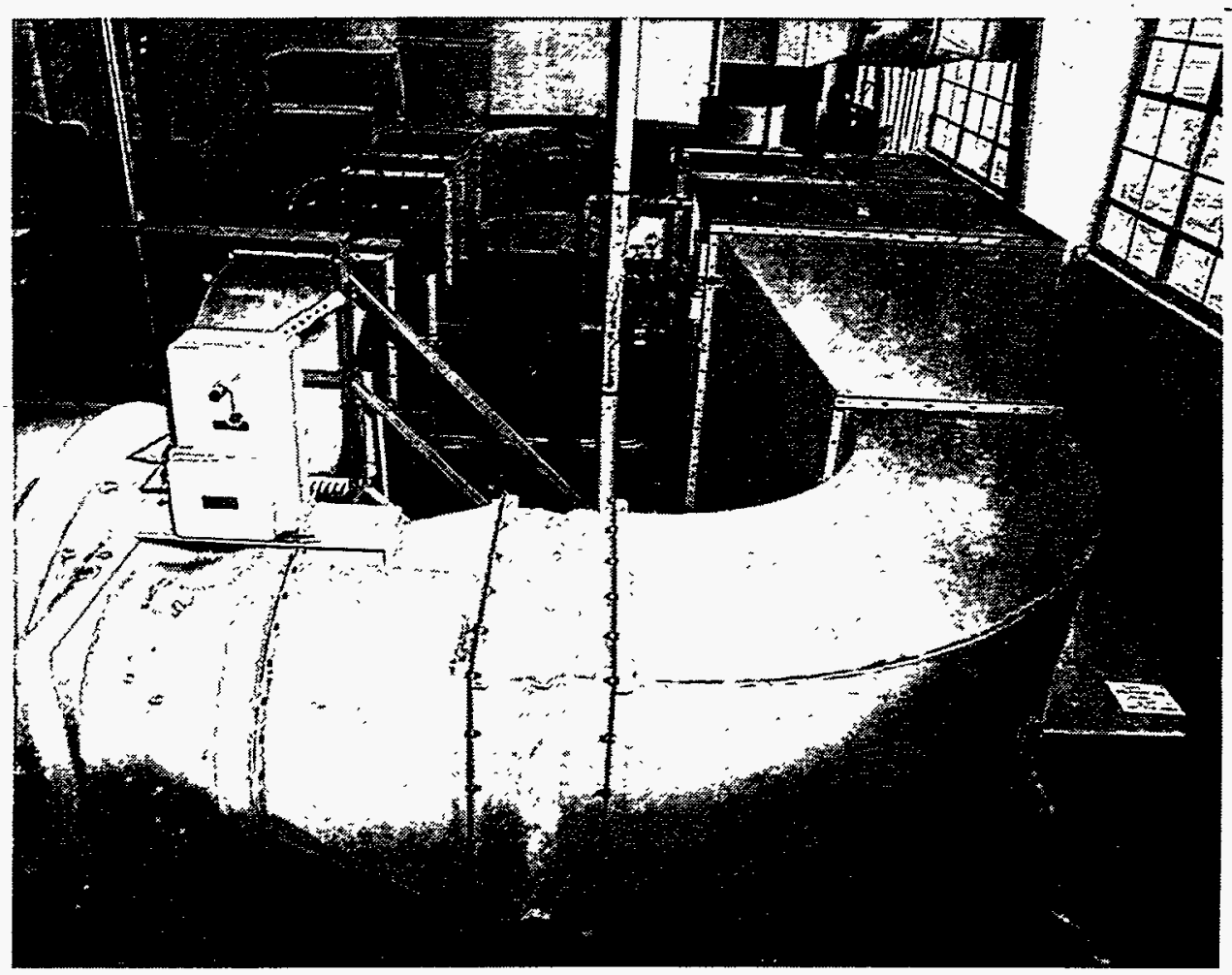

Figure 6 Pressure resistance apparatus 


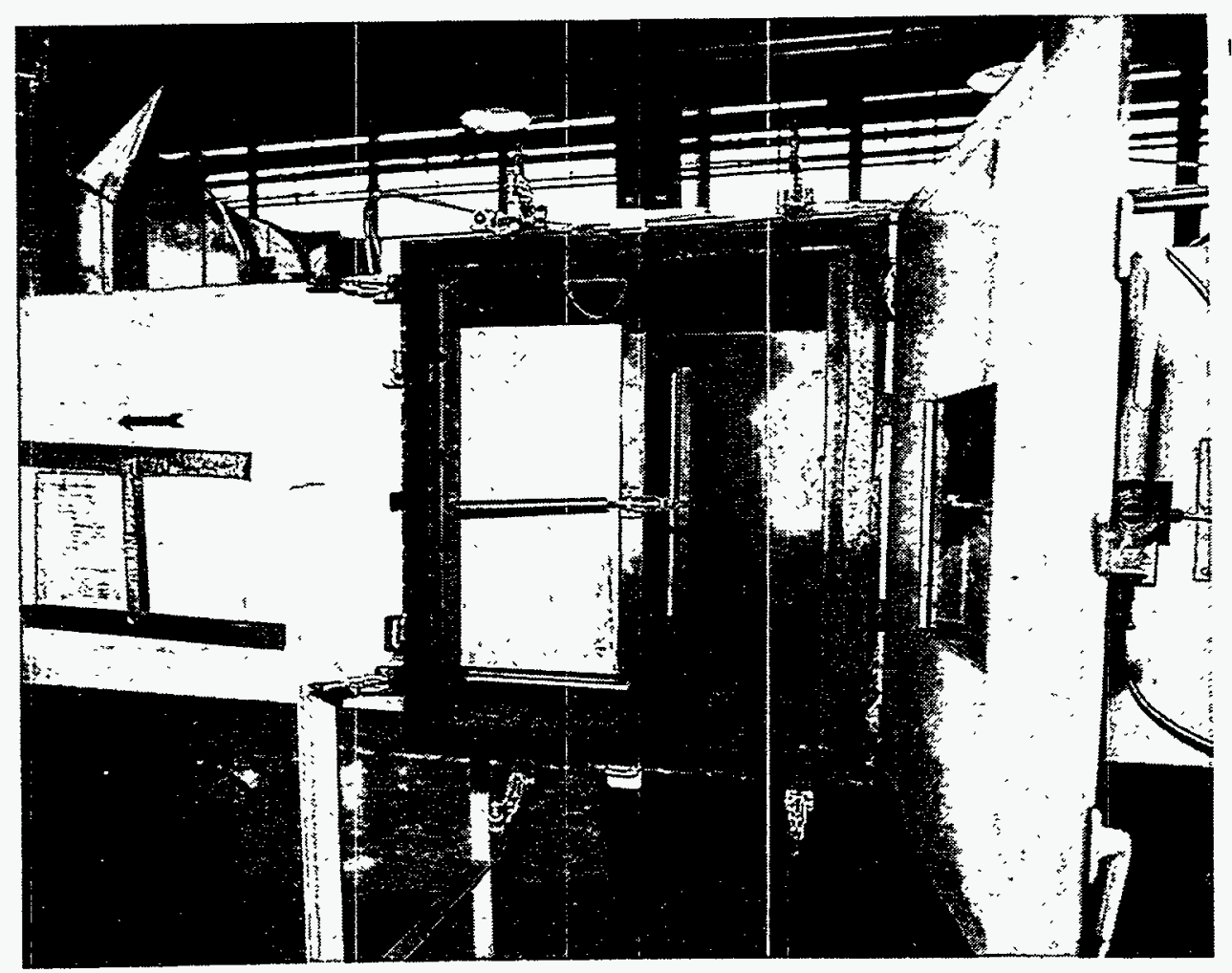

Figure 7 Standard HEPA filter mounted in the pressure resistance apparatus with access door open

The pressure resistance test consists of measuring the HEPA filter efficiency according to Military Standard MIL-STD-282 [8] before and after exposure to the overpressure for one hour. The filters are first first preconditioned in an environmental chamber held at relative humidity of $95 \%, \pm 5 \%$ and temperature at $95 \pm 5^{\circ} \mathrm{F}$ $\left(35 \pm 3^{\circ} \mathrm{C}\right)$ for 24 hours. After installing the filter in the test apparatus, the blower is started together with the introduction of steam, which condenses to water droplets, and the volume of air is increased to maintain a resistance of 10 inches water gauge $(2.5 \mathrm{kPa})$ across the filter. Water droplets are generated at a rate of one pound $\pm 1 / 4$ pound $(114 \mathrm{~g})$ per 1,000 cubic feet $\left(1,700 \mathrm{~m}^{3}\right)$ of air. At 10 inches $(2.5 \mathrm{kPa})$ of pressure drop the total air flow, with the added moisture, measures between 7,000 to $8,000 \mathrm{cfm}(11,900-13,600$ $\mathrm{m}^{3} / \mathrm{hr}$ ). This pressure is maintained on the filter for a minimum of one hour. 
Although the practice at the Edgewood Area of Aberdeen Proving Ground is to measure penetration of the filter promptly after its test, the procedure at Rocky Flats is to terminate water droplets and continue the air briefly to remove detectable water and let the filter stand over night before measuring its penetration. The Rocky Flats modification assumes that any perforations of the filter from the pressure resistance test will be detected where otherwise they might be bridged and occluded by residual moisture.

\section{Rough Handling Test}

The rough handling test has been used for many years and the test procedure is described in MIL-STD-282 [8]. The equipment, in essence, is a vibrating machine designated the Q110 and is designed to simulate transportation vibrations. Figure 8 shows a photograph of the rough handling test apparatus at the Rocky Flats Plant. It provides a platform, to which the HEPA filter is attached, and it mechanically moves the bed 200 cycles per minute

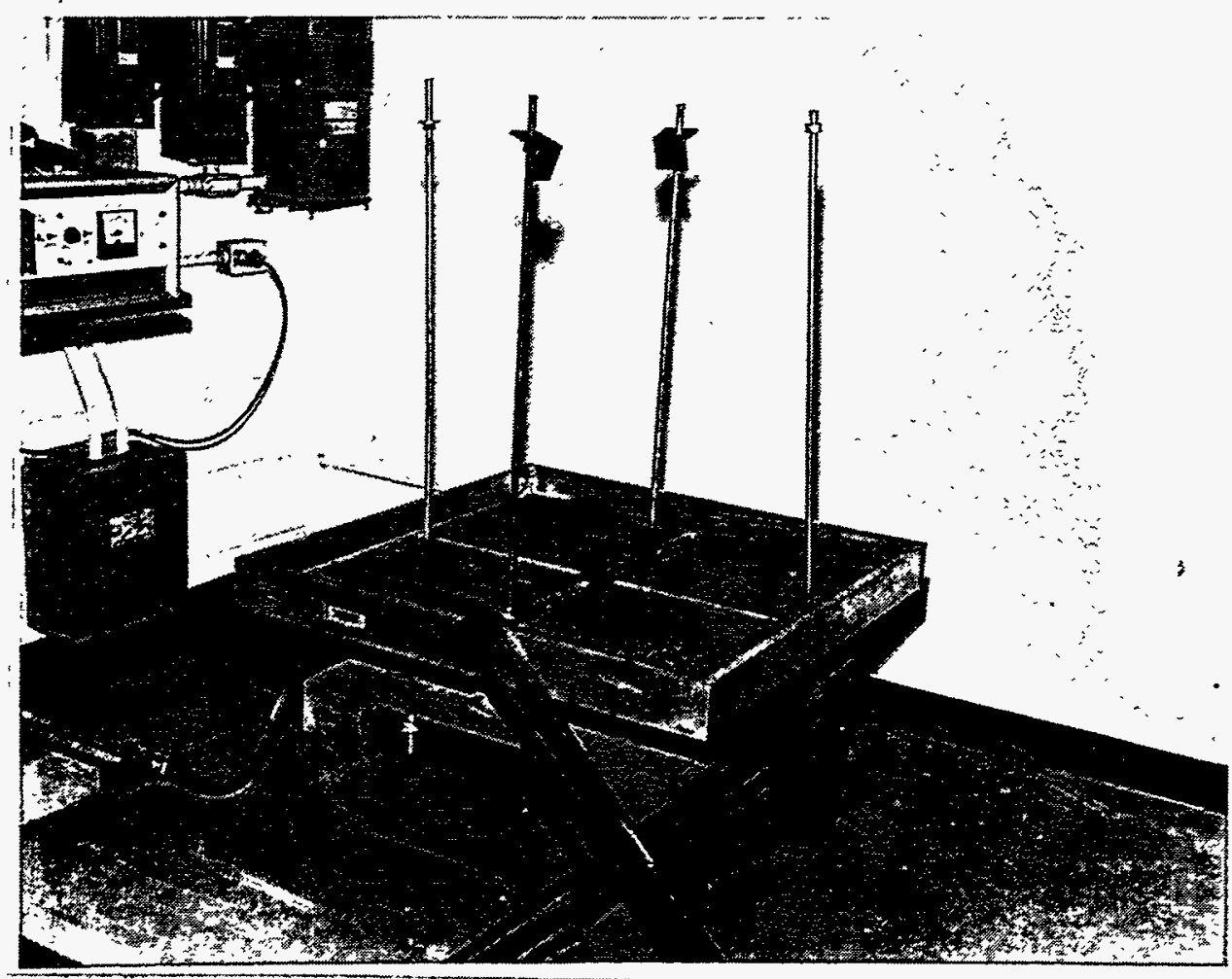

Figure 8 Rough handling test apparatus 
at an amplitude of $3 / 4$ inch for 15 minutes. A view of one of the two cams that lifts and drops the platform is shown in Figure 9. We evaluated the resistance of the box HEPA filters to rough handling by measuring the HEPA filter efficiency according to Military Standard MIL-STD-282 [8] before and after the rough handling test. The box HEPA filter was removed from its shipping carton and clamped directly on the platform. The apparatus would periodically shut down during the tests because the cam mechanism would fall out of alignment and jam. The apparatus was not designed for the heavier box HEPA filters ( 53 pounds compared to 34 pounds for the standard open face HEPA filter).

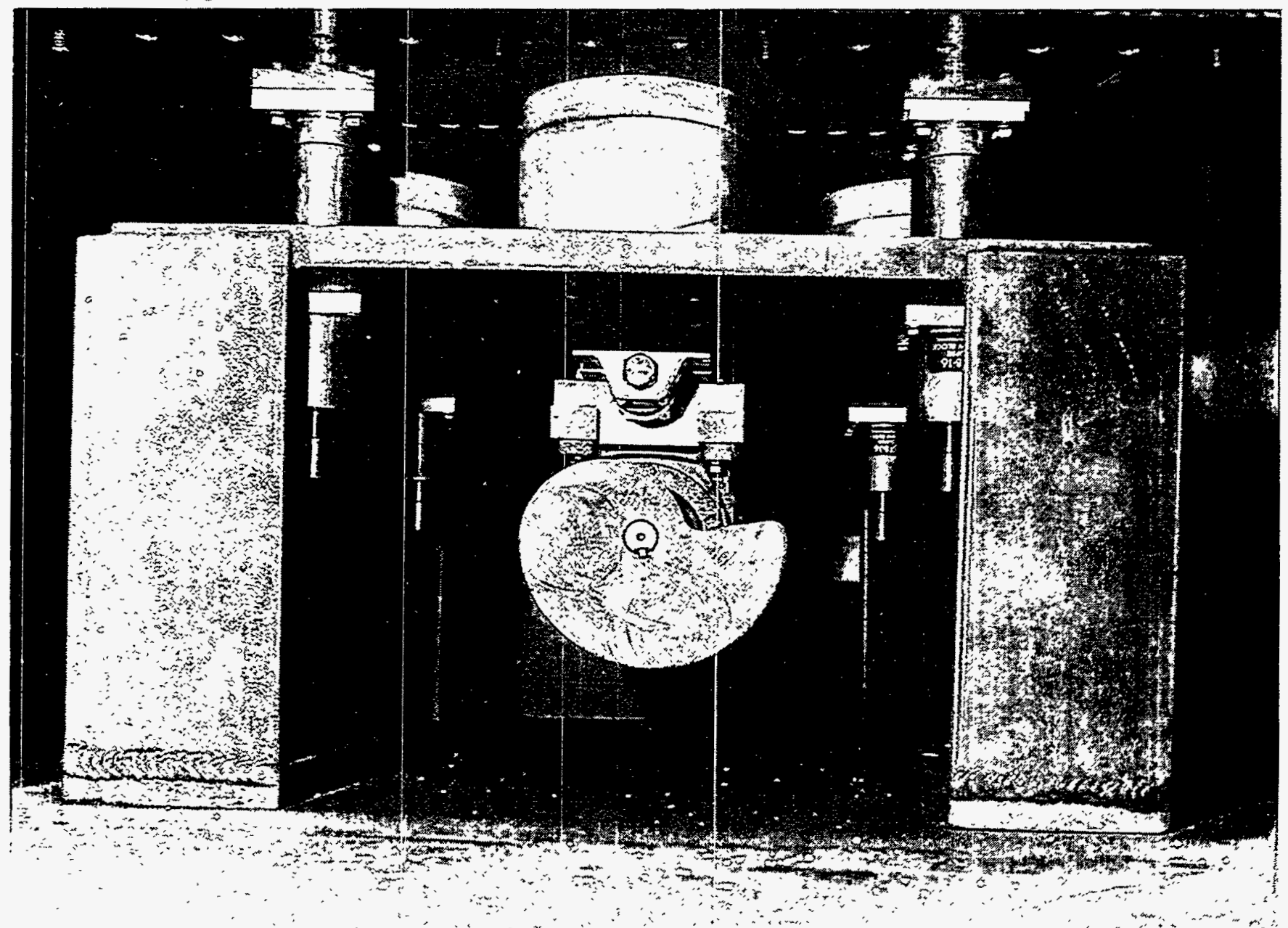

Figure 9 Cam for lift/drop platform on rough handling apparatus 


\section{Filter Qualification Test Results}

After modifying the existing filter qualification test equipment at the DOE Rocky Flats Filter Test Station, 1,000 cfm box HEPA filters from American Air Filter were tested. The filters had a plywood frame, deep-pleated medium, aluminum separators, and neoprene sealant. Table 1 shows the filter penetration measurements before and after the qualification tests for each of the box HEPA filters.

Table 1 Filter qualification test results

\begin{tabular}{|c|c|c|c|c|c|c|}
\hline \multicolumn{7}{|c|}{ Heated Air Test } \\
\hline Filter No. & \multicolumn{3}{|c|}{ Before } & \multicolumn{3}{c|}{ After } \\
\hline & $100 \%$ & $20 \%$ & $\Delta \mathrm{P}$ & $100 \%$ & $20 \%$ & $\Delta \mathrm{P}$ \\
\hline 455566 & 0.009 & 0.012 & 1.3 & 0.022 & 0.040 & 1.3 \\
\hline 41459567 & 0.012 & 0.020 & 1.3 & 0.042 & 0.072 & 1.32 \\
\hline Standard & 0.030 & - & - & 3.000 & - & - \\
\hline
\end{tabular}

\begin{tabular}{|c|c|c|c|c|c|c|}
\hline \multicolumn{9}{|c|}{ Overpressure Test } \\
\hline Filter No. & \multicolumn{3}{|c|}{ Before } & \multicolumn{3}{c|}{ After } \\
\hline & $100 \%$ & $20 \%$ & $\Delta \mathrm{P}$ & $100 \%$ & $20 \%$ & $\Delta \mathrm{P}$ \\
\hline 459549 & 0.010 & 0.012 & 1.3 & 0.010 & 0.012 & 1.3 \\
\hline 41459608 & 0.009 & 0.012 & 1.3 & 0.012 & 0.016 & 1.4 \\
\hline $459549^{\star}$ & 0.010 & 0.010 & 0.9 & 0.010 & 0.011 & 1.3 \\
\hline Standard & - & $0.030 \%$ & - & - & $0.030 \%$ & - \\
\hline
\end{tabular}

\begin{tabular}{|c|c|c|c|c|c|c|}
\hline \multicolumn{9}{|c|}{ Rough Handling Test } \\
\hline Filter No. & \multicolumn{3}{|c|}{ Before } & \multicolumn{3}{c|}{ After } \\
\hline & $100 \%$ & $20 \%$ & $\Delta \mathrm{P}$ & $100 \%$ & $20 \%$ & $\Delta \mathrm{P}$ \\
\hline 4159600 & 0.009 & 0.012 & 1.3 & 0.012 & 0.014 & 1.3 \\
\hline 459560 & 0.010 & 0.018 & 1.3 & 0.010 & 0.020 & 1.3 \\
\hline Standard & 0.030 & 0.030 & - & 0.030 & 0.030 & - \\
\hline
\end{tabular}

- Flanges were cut of the HEPA filter to reach 10 inch pressure drop.

Table 1 shows the percent penetration at 100\% flow, 20\% flow and the pressure drop (at 100\% flow) for each box HEPA filter before and after exposure to each of the three qualification tests. The required penetration values specified in ASME N509 [1] and MIL-F-51068 [2] are shown as the standard. 
Table 1 shows that the $1,000 \mathrm{cfm}$ box HEPA filters from American Air Filter readily pass the required qualification tests. In the first overpressure tests on filters 459549 and 41459608 , we were not able to expose the media to the required 10 inches of pressure because the blower could not overcome the inlet and exit restrictions of the box HEPAs. Filters 459549 and 41459608 were exposed to pressure drops of 7.1 and 8.0 inches respectively. We then cut off the inlet and exit faces of HEPA 459549 and repeated the overpressure test at the required 10 inches. The modified filter also passed the test. The higher pressure drop (1.3 inches) after the test was probably due to wet filter media.

\section{Filter Housing Leak Test}

One of the issues that Arndt [6] raised in his review of box HEPA filters was the potential for leaks through the filter housing. $\mathrm{He}$ correctly reasoned that since the box is equivalent to a filter housing, it should meet the requirements for filter housings specified in ASME N509 [1]. By the same reasoning, any open face HEPA filter that has the filter frame acting as a wall for the ventilation system should also be tested for leaks. To address this concern, we conducted a series of leak tests on both the box HEPA filter and an open face HEPA filter. Both HEPA filters had wooden plywood frames and were manufactured by American Air Filter.

The filter leaks were determined using the experimental configuration shown in Figure 10. This test configuration meets the requirements of ASME N510 [9], section 6.5.2, Duct and Housing Leak Rate Test. The box HEPA filter was sealed with a plate and gasket over both duct connections. One plate was penetrated with a pipe to apply a vacuum to the box interior. A Magnehelix pressure gage (025") and dry gas meter were connected to the pipe for measuring the vacuum and the corresponding leak flow rate. We used valve 1 to control the vacuum level on the box HEPA filter. The results of three sets of leak flow measurements at 1, 5, and 10 inches of vacuum are shown in Table 2. The filter is a $1,000 \mathrm{cfm}$ Astrocell box filter (24" $\mathrm{x}$ $24 " \times 20 "$ ), serial number 413866668 , manufactured by American Air Filter. 


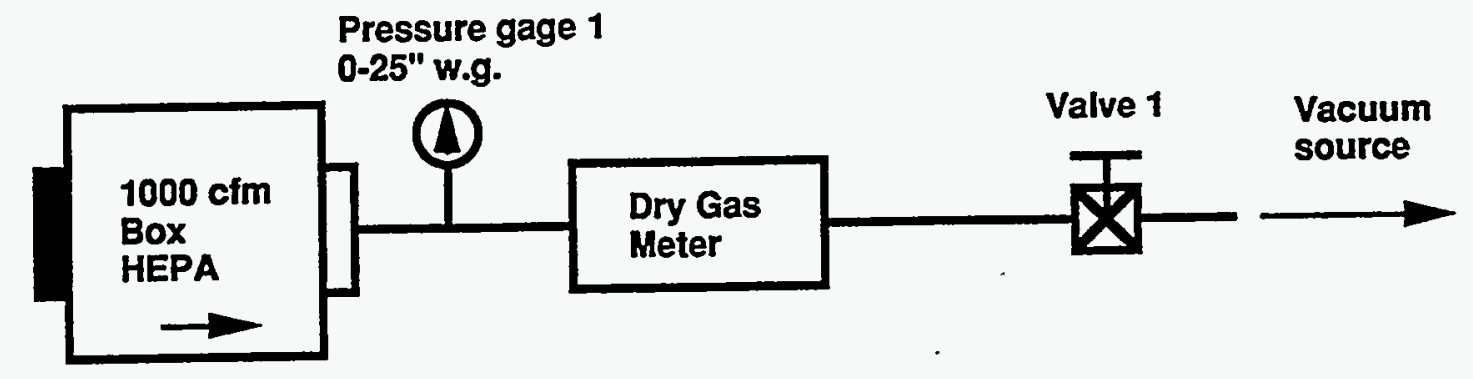

Figure 10. Schematic of test system for measuring filter frame leaks.

Table 2 Leak Measurements in Box HEPA

\begin{tabular}{|c|c|c|}
\hline Vacuum & Leak rate & $\begin{array}{l}\text { Leakage, } \\
\% \text { rated flow }\end{array}$ \\
\hline 1 inch & $4.761 / \mathrm{min}$ & $0.017 \%$ \\
\hline 5 inches & $18.01 / \mathrm{min}$ & $0.064 \%$ \\
\hline 10 inches & $31.91 / \mathrm{min}$ & $0.113 \%$ \\
\hline
\end{tabular}

Table 2 shows that the leak increases with increasing vacuum. We also computed the leakage in terms of percent of rated flow. These leaks are far lower than the allowable leakage for ESF ducts and housings, which are $0.10 \%$ according to Table B-3 of ASME N509 [1]. The leakage percentage is greater than what would occur with aerosol penetration due to particle loss in the leak paths. For comparison, we also measured the leak through the frame of a standard open face HEPA filter with the two faces sealed. The leak rate with a 10 inch vacuum was $16.4 \mathrm{1} / \mathrm{min}$. The higher leak rate with the box filter is due to the larger area of the box. In separate tests with the box under pressure, we located the source of the leaks using soap bubble tests. These tests showed the leaks occurred at the nail holes and along the butt joints. Thus we found that the measured leaks through the box frame are very low and would not restrict their use in nuclear applications due to the leak rate. 


\section{$\underline{V}$ Conclusion}

We established that the $1,000 \mathrm{cfm}$ box HEPA filters from American Air Filter have passed the heated air, overpressure and rough handling tests to qualify their use in nuclear applications. All other box HEPA filters from American Air Filter and other manufacturers must still be tested before they are qualified for use in DOE facilities. Leak tests on the box frame also show that the leaks are within the limits allowed for HEPA filter housings. However, the box filters with plywood frames that were evaluated in this study cannot be used as ESF filters unless the filters are placed in a metal housing.

Although the test results in this report only apply to the 1,000 cfm box HEPA from American Air Filter, box filters from other manufacturers and box filters from American Air Filter made using different materials are also expected to pass the required test. This follows because the only difference between a box filter and a standard open face filter is the restricted inlet and exit ports. Since the box HEPA filters from American Air Filter passed the qualification tests, any box HEPA filter made from the same materials and the same manufacturer as an open faced HEPA filter that passed the qualification test is also expected to pass. Note that the qualification test are only valid for five years.

Since box HEPA filters are not covered in any of the HEPA filter standards, an effort should be made to incorporate these filters in the applicable standards. The test facilities for qualifying HEPA filters should also be upgraded to accomodate the box HEPA filters without modifying the filters.

\section{Acknowledgment}

The authors acknowledge the support of the Office of Special Projects in DOE's Defense Programs that made this study possible. 


\section{References}

1. "Nuclear Power Plant Air-Cleaning Units and Components" ASME N509, American Society of Mechanical Engineers, 345 East 47th Street, New York, NY 10017, 1989.

2. "Filter, Particulate, High-Efficiency, Fire Resistant", Military Specification MIL-F-0051068, Commander, U. S. Army Armament, Munitions and Chemical Command, ATTN: DRSMC-CLW-E/A, Aberdeen Proving Ground, MD 21010-5423.

3. Burchsted, C.A., Fuller, A.B., and Kahn, J.E., "Nuclear Air Cleaning Handbook", NTIS, Springfield, VA , ERDA-76-21, 1976.

4. $\quad$ "High Efficiency Particulate Air Filter Units, Standard for Safety", UL 586, Underwriters Laboratories Inc., 333 Pfingsten Road, Northbrook, IL 60062, October 18, 1990.

5. "Installation of Air Conditioning and Ventilating Systems" NFPA 90A, National Fire Protection Association, 1 Batterymarch Park, P.O. Box 9101, Quincy, MA 02269-9101, August 7, 1989.

6. Arndt, T.E. "Evaluation of self-contained HEPA filter" in Proceedings of the 23rd DOE/NRC Nuclear Air Cleaning Conference, M. First, Editor, pp54-67, CONF-940738, NTIS, Springfield, VA 22161-0002, February, 1995.

7. "General Design Criteria", Department of Energy Order, DOE 6430.1A, April 6, 1989.

8. "Filter Units, Protective Clothing, Gas-Mask

Components and Related Products Performance-Test Methods", Method 105.9, Military Standard MIL-STD-282, Commanding Officer, Frankford Arsenal, Navy Department, ATTN: SMUFA-N1100, Philadelphia, PA 19137.

9. "Testing of Nuclear Air Treatment Systems", American Society of Mechanical Engineers, ASME N510-1989, 345 East 47th Street, New York, NY 10017, 1989. 